\title{
Estimation of the dental movements caused by Narval@ Oral Appliance in the treatment of adult obstructive sleep apnea hypopnea syndrome
}

JC Letievant ${ }^{1}$, G Buiret ${ }^{2}$, E Dinkel $^{3}$ and B Navailles ${ }^{4}$

${ }^{1}$ Service d'ORL et de chirurgie cervicofacial, Centre Hospitalier Lyon Sud, Chemin du Grand Revoyet, 69495 Pierre-Bénite France.

${ }^{2}$ Service d'ORL et de chirurgie cervicofaciale, Centre Hospitalier de Valence, 179 Boulevard du Maréchal Juin, 26953 Valence, France.

${ }^{3}$ Service d'ORL et de chirurgie cervicofaciale, Centre Hospitalier des Portes de Provence, Quartier Bosseret, route de Sauzet, 26200 Montélimar, France.

${ }^{4}$ Service d'ORL et de chirurgie cervicofaciale, Centre Hospitalier de Valence, 179 Boulevard du Maréchal Juin, 26953 Valence, France.

Corresponding Author: G Buiret, Service d'ORL et de chirurgie cervicofaciale, Centre Hospitalier de Valence, 159 Boulevard du Maréchal Juin, 26953 Valence, France.

Received date: January 21, 2021; Accepted date: February 12, 2021; Published date: March 13, 2021

Citation: JC Letievant, G Buiret, E Dinkel and B Navailles (2021) Estimation of the dental movements caused by Narval® Oral Appliance in the treatment of adult obstructive sleep apnea hypopnea syndrome. J, Of Clin Otori 3(1); DOI: 10.31579/2692-9562/019

Copyright: (C) 2021, G Buiret, This is an open access article distributed under the Creative Commons Attribution License, which permits unrestricted use, distribution, and reproduction in any medium, provided the original work is properly cited.

\section{Abstract}

Objective: oral appliances are one of the treatments of obstructive sleep apnea hypopnea syndrome. They all have dental anchoring points, causing potential changing in the dental occlusion with time. The aim of the study was to evaluate dental displacement induced by $\mathrm{Narval}{ }^{\circledR}$ oral appliance in the treatment of the adult mild to severe obstructive sleep apnea hyponea syndrome.

Material and methods: The study was based on 15 adults with mild to severe obstructive sleep apnea hypopnea syndrome treated with a Narval ${ }^{\circledR}$ oral appliance for more than one year. Before oral appliance delivery and more than one year after oral appliance delivery, dental impressions were performed and digitized by a 3D scanner. The dental positions were calculated by the software 3D Reshaper ${ }^{\circledR}$ and compared.

Results: The mean wearing time of the Narval ${ }^{\circledR}$ oral appliance was 13.5 months $( \pm 2.1)$. The mean mandibular advancement was $6 \mathrm{~mm}( \pm 2)$. For the maxillary arch, there was a significant distalization of molar and premolarcanine blocks from 0.12 to $0.20 \mathrm{~mm}$ (all $\mathrm{p}<0.05$ ) and a significant proclination of incisal blocks of $0.18 \mathrm{~mm}(\mathrm{p}<0.05)$. For the mandibular arch, there was a significant mesialization of the molar and premolar-canine blocks of 0.14 to $0.25 \mathrm{~mm}(\mathrm{p}<0.05)$ and a non-significant retoclination of the incisors of $0.09 \mathrm{~mm}$.

Conclusions: The Narval ${ }^{\circledR}$ oral appliance produced minimal but significant teeth movements on the maxillary and mandibular at the short and medium term.

Keywords: oral appliance; side effects; dental displacements; obstructive sleep apnea syndrome

\section{Introduction}

Oral appliances (OAs) are one of the therapeutic options for treating Obstructive Sleep Apnea Hypopnea Syndrome (OSAHS). French Health Authorities current recommend them as a second-line treatment in failure or intolerance to Continuous Positive Pressure Ventilation (CPPV) in severe OSAHS or as a first-line treatment in moderate OSAHS [1, 2]. Two concomitant mechanisms of action have been described [3-5]: 1. the increase in the diameter of the upper airways by advancing the mandible: anteriorization of retrobasilingual space, lateral expansion of pharyngeal walls and soft palate; and 2. the action on the stretch receptors of the genioglossus muscle, probably by decreasing its hyperactivity. There are many types of OAs, with varying efficacy and tolerances [6]. Among them, the efficacy of Narval@ OA has been reported in the short [7-9] and long terms [10].

On the other hand, all OAs anchor on dental arches. Their use can therefore lead to a change in dental occlusion, by dental and/or bone bases displacement, in the short-, medium- and long-terms [11-17].

The aim of this study was to evaluate the dental displacement caused by the Narval ${ }^{\circledR}$ OA in adult patients with mild to severe OSAHS

\section{Methods}

\section{Population}

We conducted a comparative "before and after" study without control. All patients treated by OA for more than a year for a mild to severe OSAHS 
who consulted in our unit between 03/02/2010 and 31/08/2011 were eligible.

All patients were carriers of a Narval ${ }^{\circledR}$ Computer-Aided Design and Computer-Aided Manufacturing OA, manufactured by Resmed Laboratory (Saint Genis Laval, France). It is a custom-made bibloc-type OA made of semi-rigid gutters articulated by a system of triangles and connectors for titration (Figure 1).

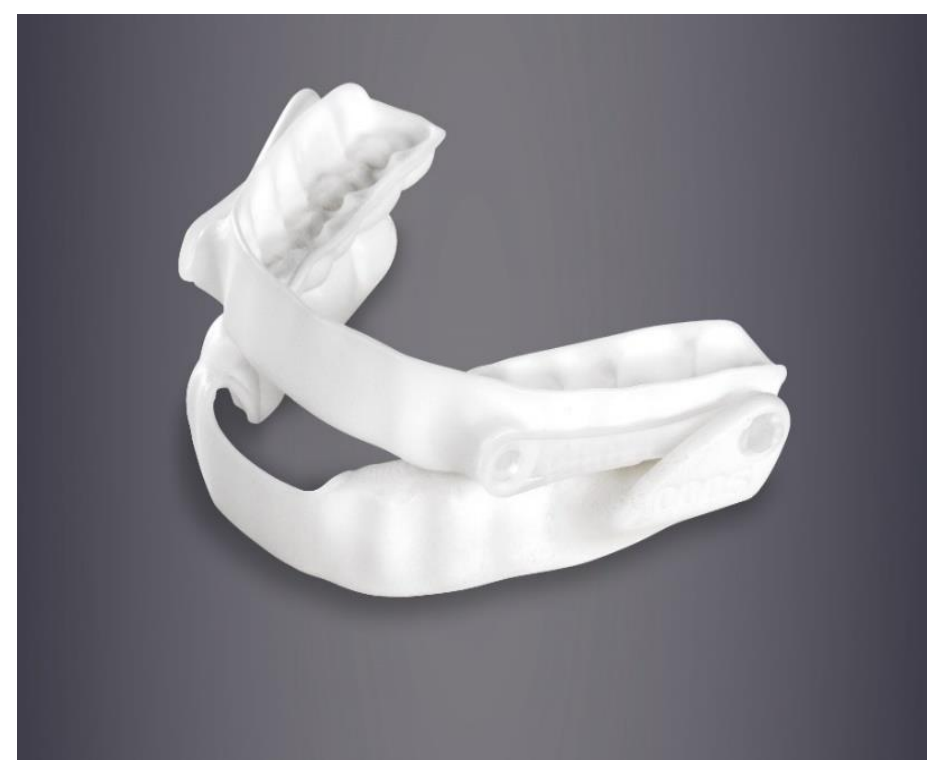

Figure 1. Narval® OA (courtesy Resmed Laboratory)

The indications and contraindications of the OA were described by Clark [18].

The non-inclusion criteria of the study were: poor compliance at the OA daily port (less than five days per week), a decrease of less than $50 \%$ of the apnea hypopnea index thanks to the OA, air bubbles in the dental prints, a poor-quality scanned plaster dental print, or a modification of the dental arch by dental care.

The main aim of the study was to compare the dental position per teeth block before the OA to at least one year after OA use.

The primary outcome was dental geolocation. The position of the points before the OA was compared to that after the wearing of the OA of at least one year.

The secondary objective was to determine the direction of dental modifications if the primary aim was met.

The secondary outcome was dental geolocation according to possible axes of modification: mesialization, distalization, vestibulization, linguoversion, ingression and aggression.

\section{Process of the OA manufacturing and the study}

The process of OA manufacturing in our otorhinoloaryngology unit has already been reported in other articles $[9,10,19]$. In summary, a complete otorhinoloaryngology and dental clinical examination, as well as an orthopantomography and a profile teleradiography, were performed prior to the initial dental printing, i.e. before the OA treatment was implemented, allowing the manufacture of OA. The second dental prints were taken more than a year from OA delivery under the same conditions.

The prints were made with Zerosil ${ }^{\circledR}$ soft, vulcanizing silicone by addition, suitable for taking situation prints. They were then sent to the OA production site (Resmed Laboratory, Saint Genis Laval, France). A positive moulding was made, allowing to recreate the patient's dental occlusion. This moulding was then digitized. The position of each tooth was determined by the geolocation of an average of 60 points per tooth. The comparison of dental occlusions before/at least one year after wearing OA was carried out with the 3D Reshaper® software by calculating the modification of distances and dental positioning. The final accuracy of the procedure was in the order of one-tenth of a millimeter.

The results provided information on the variability in the space of each tooth: mesialization (anterior displacement), distalization (posterior displacement), vestibulization (external lateral displacement), linguoversion (internal lateral displacement), ingress and egress.

For the calculation of dental mobility, the teeth were grouped by block:

Block \#1: left molar teeth (teeth \# 8, 7, 6)

Block \#2: left premolar and canine teeth (teeth \# 5, 4, 3)

Block \#3: incisive teeth (teeth \# 2, 1, 1, 2)

Block \#4: right premolar and canine (teeth \# 3, 4, 5)

Block \#5: right molar teeth (teeth \# 6, 7, 8)

Each block was also distinguished by the letter $S$ (as superior) for maxillary teeth and the letter L (as lower) for mandibular teeth.

\section{Statistical analayses}

After checking the normal distribution of the data, comparisons of means on paired data were made (ANOVA).

The population size to be included was made with the R software (library pwr) on paired data. A dental displacement difference of $0.1 \mathrm{~mm}$ with an $\alpha$-risk of 0.05 and a power of 0.8 led to 787 patients to integrate.

The tests were carried out on the software spss for Windows version 12 (IBM, Armonk, NY).

\section{Results}

Of the 40 eligible patients, 15 patients were finally included (37.5\%, 4 men and 11 women). The flowchart is presented in the (Figure 2).

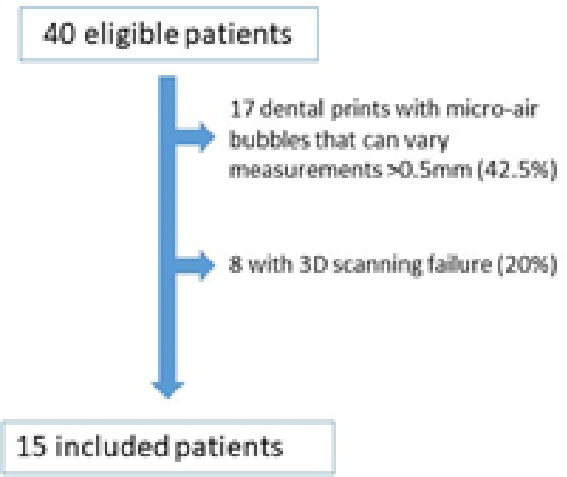

\section{Figure 2: flowchart of the study}

The mean age of the patients was 50.5 years $( \pm 20.5)$. The mean duration of the OA was 13.5 months $( \pm 2.1)$. The average mandibular propulsion was $6 \mathrm{~mm}( \pm 2)$.

Table 1 shows the mean dental mobilization. There was a significant dental displacement of each mandibular and maxillary dental block. 


\begin{tabular}{|l|l|l|l|}
\hline & & IC95\% & $\mathrm{p}$ \\
\hline Block 1L & $0.218( \pm 0.136)$ & {$[0.143 ; 0.294]$} & $<10^{-4}$ \\
\hline Block 2L & $0.229( \pm 0.112)$ & {$[0.167 ; 0.291]$} & $<10^{-4}$ \\
\hline Block 3L & $0.255( \pm 0.150)$ & {$[0.172 ; 0.338]$} & $<10^{-4}$ \\
\hline Block 4L & $0.251( \pm 0.164)$ & {$[0.160 ; 0.341]$} & $<10^{-4}$ \\
\hline Block 5L & $0.190( \pm 0.176)$ & {$[0.093 ; 0.287]$} & $<10^{-3}$ \\
\hline Block 1S & $0.160( \pm 0.135)$ & {$[0.090 ; 0.240]$} & $<10^{-3}$ \\
\hline Block 2S & $0.163( \pm 0.053)$ & {$[0.133 ; 0.192]$} & $<10^{-4}$ \\
\hline Block 3S & $0.308( \pm 0.185)$ & {$[0.206 ; 0.410]$} & $<10^{-4}$ \\
\hline Block 4S & $0.208( \pm 0.148)$ & {$[0.126 ; 0.290]$} & $<10^{-4}$ \\
\hline Block 5S & $0.231( \pm 0.167)$ & {$[0.139 ; 0.324]$} & $<10^{-4}$ \\
\hline
\end{tabular}

Table 1. Mean dental movements ( \pm standard-error) $(\mathrm{mm})$

Mean dental block displacements and their directions are reported in (Figure 3).

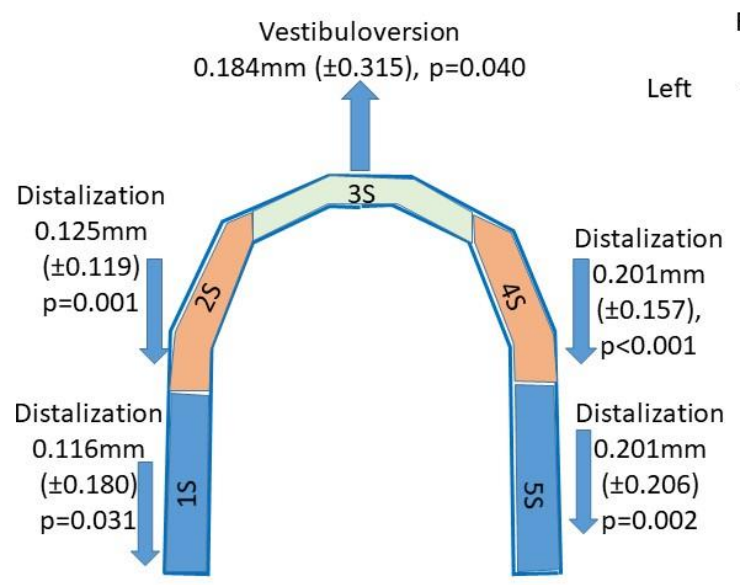

Maxillary arch (superior view)

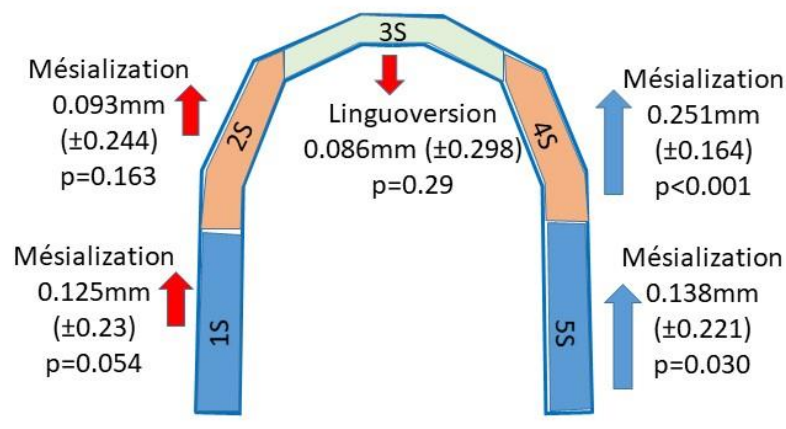

Mandibulararch (superior view)

Arrows represent the directions of significant (in blue) and non-significant dental movements (in red)

Figure 3. Representation of the analysis of mean dental movements by dental block and direction.

In addition, there were dental height movements:

- a sub-millimeter ingress for some teeth in the maxillary arch: 27 for three patients, 17 for four patients, and 16 for two patients.

- an egress for some teeth of the mandibular arch: 37, 36, 47 and 46 in a single patient.

Dental displacement per block per patient is reported in Appendix 1.

\section{Discussion}

This study showed that Narval ${ }^{\circ}$ OA caused a significant dental displacement in every block, variable in importance and direction according to the dental block. It has led to a distalization of the maxillary teeth and a mesialization of the mandibular teeth. But amplitudes of dental movements were low $(0.1$ to $0.25 \mathrm{~mm})$.

Previous studies have shown that there was dental and bone modifications as well as dental displacement, regardless of the type of OA used [12-17, 20]. Force vectors directions are different from one OA to another, depending on the design [6]. Combined with the teeth on which these vectors are applied (mono- or multi-radicular), dental movements can be anticipated. For instance, Marklund et al. [13], using a bibloc OA in propulsion with a mean mandibular advancement comparable to our, showed a mesialization of 0.3 to $0.6 \mathrm{~mm}$ of molars and 0.4 to $0.5 \mathrm{~mm}$ of premolars, regardless of upper and lower dental arches. Hammond et al. [14] studied the dental and bone bases movements of a bibloc OA with cylinders propulsion (equivalent to a Somnodent ${ }^{\circledR}$ OA from the Somnomed laboratory). They also found a mesialization of the mandibular molars of $0.3 \pm 0.77 \mathrm{~mm}$. In our series, dental displacement seemed less $(0.1$ to $0.25 \mathrm{~mm})$.

Herbst-type OAs would cause dental movements opposite the Narval ${ }^{\circledR}$ OA. For molars and premolars their respective movements could be explained by the differences in forces exerted by these two types of OAs [21-23], as well as support on mandibular monoradicular teeth, more prone to movements compared to multiradicular teeth. Herbs-type OAs exert antero-lower direction forces resulting in the mesialization of the teeth of the maxillary and mandibular arches. Narval ${ }^{\circledR}$ OA exerts posterior forces for maxilla and anterosuperior for the mandible [21], resulting in a distalization of the teeth of the maxillary arches and a mesialization on the mandibular arch. For incisors, the contrast of movement observed between the Herbst-type OAs and the Narval ${ }^{\circledR}$ OA could also be partly explained by the absence of total recovery at the 
incisors with the Narval® OA: the anterior headband being in contact only with the anterior facet of the incisors.

Dental displacement studies also focused on studying the anteroposterior movements of incisors. Wearing an Herbst-type OA resulted in a mean palatoversion of the upper incisors [12-15, 20], from $0,8^{\circ} \pm 4,7^{\circ}$ [15], to $1,9^{\circ} \pm 2,9^{\circ}$ [16]; it resulted in a vestibuloversion of the lower incisors of $0,96^{\circ} \pm 0,30^{\circ}$ i.e. $0.52 \pm 0.12 \mathrm{~mm}$ [14], to $4.9^{\circ}$ [15]. Alessandri-Bonetti et al. [17] found with the Silensor® OA a mean palatoversion of the upper and lower incisors of $0.4^{\circ} \pm 0.72^{\circ}$ and $2.27^{\circ} \pm 1.38^{\circ}$ respectively. In our study, the Narval ${ }^{\circ}$ OA resulted in a mean upper incisor vestibuloversion of $0.18 \mathrm{~mm}$ and a mean linguoversion of the lower incisors of $0.09 \mathrm{~mm}$. It is interesting to note that the Silensor ${ }^{\circledR}$ OA also found a tendency to lingualize the teeth of the lower dental arch [17], consistent with our study.

Narval ${ }^{\circledR}$ OA would therefore appear to be one of OAs with less dental resonance for incisors, premolars and molars compared to other OAs.

The use of CPPV for more than 2 years has been shown to alter the occlusion between dental arches and leaded to a reclining of the upper incisors and a significant retrusion of the anterior maxilla associated with a decrease in convexity [24]. A $0.1 \pm 0.6$-mm-anteroposterior modification was also described under CPPV, as well as a decrease in the number of dental contact points at the premolar level [9]. CPPV would therefore result in dental movements in adults that were not intellectually obvious because CPPV device has no direct interaction with the teeth. Our study highlighted a maximal mean dental movements of $0.3 \mathrm{~mm}$ with consistent therapeutic efficacy, which would seem to be quite acceptable compared to dental movements $(0.1 \pm 0.6 \mathrm{~mm})$ induced by CPPV [11].

Finally, there are spontaneous dental changes. In humans, dental spontaneous movements are mesial and vertical, explained by the "law of tangent" $[25,26]$. This poses the problem of comparability of studies, even in the case of a control case study. Even a study on twins would not ensure of the complete comparability of the arms.

\section{Limitations of our study}

Our study is not without criticism. Firstly, we have chosen to quantify all dental movements in $\mathrm{mm}$ compared to the initial dental joint without referring to a bone base, whereas most studies performed their calculations on profile teleradiographies, i.e. on a bone base. We have chosen this method because the calculation of bone base modification on face and profile teleradiography does not seem accurate enough compared to a digital analysis. The ideal would therefore be a method combining dental displacement and modification of the bone bases, by digitization. We have already shown a marked improvement in the quality of digital dental printing in the absence of coloured amalgams or dentures [19].

In addition, the distant date of its realization can also be criticized. Indeed, it was carried out shortly after the establishment of the Narval@ OA following the princeps study [7] in which we had participated. It was the subject of a MD thesis and was then forgotten. Recent publishing work $[9,10,19]$ "exhumed" it and its interest rediscovered.

The small population size of our sample (15 patients vs. 787 to be integrated according to the population size calculation) does not prevent statistical tests from reaching a satisfactory level of significance. This low number does not reduce the power of the study.

Finally, if the high rate of noncompliance of the dental prints $(63.5 \%)$ decreases the strength of our analysis, attrition bias is not as important because noncompliance has no reason to be more frequent in the event of dental displacement than in their absence. This ratio can be explained by the moment when the study was conducted. Indeed, the digitalized comparison technic was quite new. Now the 3D acquisition of dental prints should ease this comparison [19].

\section{Conclusion}

Our results confirmed that there was a significant but minimal dental displacement with the use of the Narval ${ }^{\circledR} \mathrm{OA}$, and that it would appear to be less important than with the use of a Herbst-type OA in the short to medium-term. A precise method of measuring both movements of bone bases and teeth should make it possible to be more precise.

\section{Supplementary materials}

\section{Legend of Appendix 1}

P: Patient number. T: oral appliance Duration (months). Min: Minimal mobility $(\mathrm{mm})$. Max: maximum mobility $(\mathrm{mm})$. Mean: average mobility of the block (mm). Dir: main axis of mobility. /yr: mobility (mm/year).

$\mathrm{X}$ : event taken into account for the calculation of average and mobility per year. The number corresponds to the numbering of the tooth. U: Unusable information due to a deformation of the dental print or the addition of significant material. E: tooth Egress. I: tooth Ingress. O: dental Overlaps on the block.

Axis of direction of the mobility of the block: M: mesialization. D: distalization. V: vestibuloversion. L: lingoversion. ML: mesialization and lingoversion. MV: mesialization and vestibuloversion. DV: distalization and vestibuloversion. DL: distalization and linguoversion.

\section{Conflict of Interest}

No conflict of interest to declare

\section{Reference}

1. Santé HAd. (2014) Comment prescrire les dispositifs médicaux de traitement du syndrome d'apnées hypopnées obstructives du sommeil chez l'adulte.

2. Ramar K, Dort LC, Katz SG, Lettieri CJ, Harrod CG, Thomas SM, et al. (2015) Clinical Practice Guideline for the Treatment of Obstructive Sleep Apnea and Snoring with Oral Appliance Therapy: An Update for 2015. Journal of clinical sleep medicine : JCSM : official publication of the American Academy of Sleep Medicine. 11:773-827

3. Ferguson KA, Cartwright R, Rogers R, Schmidt-Nowara W. (2006) Oral appliances for snoring and obstructive sleep apnea: a review. Sleep. 29:244-62

4. Almeida FR, Tsuiki S, Hattori Y, Takei Y, Inoue Y, Lowe AA. (2011) Dose-dependent effects of mandibular protrusion on genioglossus activity in sleep apnoea. Eur Respir J. 37:209-12

5. Clark GT, Sohn JW, Hong CN. (2000) Treating obstructive sleep apnea and snoring: assessment of an anterior mandibular positioning device. J Am Dent Assoc. 131:765-71

6. Buiret G, Chidiac F. (2020) Oral appliances for obstructive sleep apnoea: What can we expect? Rev Mal Respir.

7. Vecchierini MF, Leger D, Laaban JP, Putterman G, Figueredo M, Levy J, et al. (2008) Efficacy and compliance of mandibular repositioning device in obstructive sleep apnea syndrome under a patient-driven protocol of care. Sleep medicine. 9:762-9

8. Vecchierini MF, Attali V, Collet JM, d'Ortho MP, El Chater P, Kerbrat JB, et al. (2016) A custom-made mandibular repositioning device for obstructive sleep apnoea-hypopnoea syndrome: the ORCADES study. Sleep medicine. 19:131-40

9. Buiret G, Bechara M, Plouin-Gaudon I, Bavozet F, Dancea O, Pujo K, et al. (2001) Oral appliances may be effective in sleep apnea syndrome beyond classical predictive factors. Laryngoscope.

10. Buiret G, Chidiac F. (2020) Long-term oral appliances for moderate to severe sleep apnea syndrome tended to lose efficacy. J Sleep Med Dis. 6:1112 
11. Doff MH, Finnema KJ, Hoekema A, Wijkstra PJ, de Bont LG, Stegenga B. (2013) Long-term oral appliance therapy in obstructive sleep apnea syndrome: a controlled study on dental side effects. Clin Oral Investig. 17:475-82

12. Almeida FR, Lowe AA, Otsuka R, Fastlicht S, Farbood M, Tsuiki S. (2006) Long-term sequellae of oral appliance therapy in obstructive sleep apnea patients: Part 2. Study-model analysis. American journal of orthodontics and dentofacial orthopedics : official publication of the American Association of Orthodontists, its constituent societies, and the American Board of Orthodontics. 129:205-13

13. Marklund M, Franklin KA, Persson M. (2001) Orthodontic sideeffects of mandibular advancement devices during treatment of snoring and sleep apnoea. European journal of orthodontics. 23:135-44

14. Hammond RJ, Gotsopoulos H, Shen G, Petocz P, Cistulli PA, Darendeliler MA. (2007) A follow-up study of dental and skeletal changes associated with mandibular advancement splint use in obstructive sleep apnea. American journal of orthodontics and dentofacial orthopedics : official publication of the American Association of Orthodontists, its constituent societies, and the American Board of Orthodontics. 132:806-14

15. Robertson C, Herbison P, Harkness M. (2003) Dental and occlusal changes during mandibular advancement splint therapy in sleep disordered patients. European journal of orthodontics. 25:371-6

16. Marklund M. (2006) Predictors of long-term orthodontic side effects from mandibular advancement devices in patients with snoring and obstructive sleep apnea. American journal of orthodontics and dentofacial orthopedics : official publication of the American Association of Orthodontists, its constituent societies, and the American Board of Orthodontics. 129:214-21

17. Alessandri-Bonetti G, D'Anto V, Stipa C, Rongo R, IncertiParenti S, Michelotti A. (2017) Dentoskeletal effects of oral appliance wear in obstructive sleep apnoea and snoring patients. European journal of orthodontics. 39:482-8

18. Clark GT. (1998) Mandibular advancement devices and sleep disordered breathing. Sleep medicine reviews. 2:163-74

19. Buiret G, Savary T. (2020) Comparison of the quality of oral appliance manufactured with an intra-oral scanner versus the alginate method. J Sleep Med Dis. 6:1111.

20. Almeida FR, Lowe AA, Sung JO, Tsuiki S, Otsuka R. (2006) Long-term sequellae of oral appliance therapy in obstructive sleep apnea patients: Part 1. Cephalometric analysis. American journal of orthodontics and dentofacial orthopedics : official publication of the American Association of Orthodontists, its constituent societies, and the American Board of Orthodontics. 129:195-204

21. Cheze L, Navailles B. (2006) Impact de deux orthèses d'avancée mandibulaire sur l'articulation temporomandibulaire. ITBMRBM. 27:233-7

22. Cohen-Levy J, Petelle B, Pinguet J, Limerat E, Fleury B. (2013) Forces created by mandibular advancement devices in OSAS patients: a pilot study during sleep. Sleep \& breathing Schlaf \& Atmung. 17:781-9

23. Lee JS, Choi HI, Lee H, Ahn SJ, Noh G. (2018) Biomechanical effect of mandibular advancement device with different protrusion positions for treatment of obstructive sleep apnoea on tooth and facial bone: A finite element study. Journal of oral rehabilitation. 45:948-58

24. Tsuda H, Almeida FR, Tsuda T, Moritsuchi Y, Lowe AA. (2010) Craniofacial changes after 2 years of nasal continuous positive airway pressure use in patients with obstructive sleep apnea. Chest. 138:870-4

25. Orthlieb JD, Laurent M. (2000) Influence of saggital inclination of the teeth and the orientation of the occlusal plane on mesial drift in the dental arch. L' Orthodontie francaise. 71:287-94

26. Page HL. (1952) The occlusal curve. Dental Digest. 19-21.
This work is licensed under Creative Commons Attribution 4.0 License

\section{To Submit Your Article Click Here: Submit Manuscript}

DOI: $10.31579 / 2692-9562 / 019$

\footnotetext{
Ready to submit your research? Choose Auctores and benefit from:

* fast, convenient online submission

* rigorous peer review by experienced research in your field

* rapid publication on acceptance

* authors retain copyrights

* unique DOI for all articles

* immediate, unrestricted online access
}

At Auctores, research is always in progress.

Learn more www.auctoresonline.org/journals/journal-of-clinicalotorhinolaryngology 